\title{
Autoimmune thyroid disease in pregnancy
}

\section{P. A. Sailakshmi, Pavana Ganga A*, Rekha BR, Suhasini S. Akash}

\begin{abstract}
Department of Obstetrics and Gynaecology, Rajarajeshwari Medical College and Hospital, Bangalore, Karnataka, India
\end{abstract}

Received: 19 February 2014

Accepted: 8 March 2014

\author{
*Correspondence: \\ Dr. Pavana Ganga A, \\ E-mail: sriganga_977@rediffmail.com
}

(C) 2014 Sailakshmi MPA et al. This is an open-access article distributed under the terms of the Creative Commons Attribution Non-Commercial License, which permits unrestricted non-commercial use, distribution, and reproduction in any medium, provided the original work is properly cited.

\begin{abstract}
Background: Maternal thyroid dysfunction is the common endocrinological disorder during pregnancy. It is associated with adverse maternal and foetal outcomes like pre-eclampsia, GDM, preterm, IUGR and miscarriage. Objective of this study was to study the prevalence of thyroid dysfunction in women with thyroid autoimmunity and its relation with adverse maternal and foetal outcomes.

Methods: It was an observational study undertaken at RRMCH from May-2013 to Oct-2013. Pregnant women were screened for thyroid dysfunction. Women with altered thyroid function tests were screened for anti TPO antibodies. Mothers with thyroid dysfunction and anti TPO antibody positive were compared with anti TPO negative mothers.

Results: Study group included 1000 pregnant women, 126 women had hypothyroidism. Anti TPO antibodies were positive in 26 women. Prevalence of hypothyroidism and autoimmunity were $7.5 \%$ and $12.8 \%$ respectively. $46.2 \%$ women with hypothyroidism and thyroid autoimmunity had PE, P value $<0.01,7 \%$ had GDM with $\mathrm{P}$ value $<0.603$, $15.4 \%$ had IUGR with $p$ value of $0.033 .7,7 \%$ women had IUD.

Conclusions: Hypothyroidism and thyroid autoimmunity are common during pregnancy. They are associated with adverse maternal and foetal outcome. Screening for thyroid dysfunction and early initiation of treatment can prevent adverse maternal and fetal outcome.
\end{abstract}

Keywords: Thyroid autoimmunity, Hypothyroidism, Anti TPO antibodies

\section{INTRODUCTION}

Thyroid dysfunction and thyroid autoimmunity are common among women of reproductive age. ${ }^{1}$ Epidemiological studies in Indian population has shown a significant prevalence of clinical and subclinical hypothyroidism in women. ${ }^{2}$ The prevalence of thyroid dysfunction during pregnancy is estimated to be $2-5 \%$. $^{2}$

Thyroid autoantibodies are found in $10-20 \%$ of women of reproductive age. ${ }^{7}$

Majority of the women who test positive for thyroid autoantibodies are euthyroid. Prevalence of hypothyroidism in India ranges from $6.47 \%-14.3 \%{ }^{4}$

\section{Physiological changes of Thyroid during Pregnancy}

Normal pregnancy is associated with significant changes in maternal thyroid physiology. Beta-hCG has a thyrotrophic activity and shares $85 \%$ homology with beta subunit of TSH. As a result of this TSH level decreases in early pregnancy in comparison to non-pregnant women. ${ }^{5,6}$ Total $\mathrm{T}_{3}$ and $\mathrm{T}_{4}$ levels increase by $30-40 \%$ owing to the increase in thyroid binding globulin levels. Changes in the levels of free $\mathrm{T}_{3}$ and $\mathrm{T}_{4}$ during pregnancy are controversial.

Serum TSH concentration is the most reliable and inexpensive test for assessing thyroid function in pregnancy. Diagnosing thyroid dysfunction during pregnancy may be complicated due to the impact of 
pregnancy on thyroid homeostasis that can make interpretation of thyroid function difficult. Use of trimester specific and assay specific TSH normal range is recommended. In the first trimester of pregnancy normal $\mathrm{TSH}$ is $\leq 2.5 \mathrm{mIU} / 1$ and in second and third trimester $\leq 3$ $\mathrm{mIU} /{ }^{6-8}$

Autoimmune thyroid dysfunction is the common cause of both hypothyroidism and hyperthyroidism. Graves' disease accounts for $85 \%$ of all cases of hyperthyroidism, whereas Hashimoto's thyroiditis is the common cause of hypothyroidism.

The presence of thyroid autoantibodies might be a marker of underlying subtle alteration in thyroid reserve. A reduction in the functional reserve of the thyroid gland associated with reduced adaptation to the physiological changes of pregnancy could contribute to minor changes in circulating thyroid hormone concentrations. The increase in thyroid stimulating hormone concentrations in pregnant women with thyroid autoantibodies supports this hypothesis. ${ }^{16}$

There is evidence that there is an alteration in cytokine expression by peripheral $\mathrm{T}$ lymphocytes in women positive for thyroid antibodies outside of pregnancy. Pregnancy is an inflammatory process involving a shift in the regulation of cytokine networks within the local placental-decidual environment. Dysregulation of local inflammatory processes can be associated with miscarriage and premature delivery. The presence of thyroid autoantibodies reflects a generalised activation of the immune system and specifically an activity of the immune system at the fetal-maternal interface. Thyroid hormones can directly influence angiogenic growth factor and cytokine production as well as trophoblast proliferation, survival, and invasion. ${ }^{7,8,17}$ This probably explains the role of thyroid autoimmunity in causing adverse effects like miscarriage, preterm delivery, preeclampsia, abruption placenta, anaemia, low birth weight babies, postpartum haemorrhage.,

\section{Objectives}

- To study the prevalence of thyroid autoimmunity in pregnant women

- To study the effect of thyroid autoimmunity on maternal and fetal outcome

\section{METHODS}

It was an observational clinical study conducted at RRMCH, over a period of six months. Study group included pregnant women attending antenatal clinic at RRMCH from May-13 to Oct-13.They were subjected to thyroid screening using chemiluminescent assay. Women with abnormal thyroid profile were included in the study group. They were screened for presence of anti-thyroid antibodies. Pregnancy outcomes of women with anti TPO antibodies positive were compared with anti TPO antibody negative women. Women with other autoimmune disorders, hypothyroidism on treatment were excluded from the study.

TSH was done by using ultra-sensitive sandwich chemiluminescent immunoassay. $\mathrm{T}_{3}$ and $\mathrm{T}_{4}$ were done by competitive chemiluminescent immunoassay. Anti TPO antibodies was done using fully automated chemiluminescent immunoassay.

Table 1: Normal reference range.

\begin{tabular}{|ll|}
\hline Parameter & Normal range \\
\hline $\mathrm{TSH}$ & $0.3-5.5 \mu \mathrm{IU}$ \\
\hline $\mathrm{T}_{3}$ & $60-200 \mathrm{ng} / \mathrm{dl}$ \\
\hline $\mathrm{T}_{4}$ & $4.5-12 \mu \mathrm{g} / \mathrm{dl}$ \\
\hline Anti TPO ab & $<35 \mathrm{IU}-$ Negative, $>35$ IU-Positive \\
\hline
\end{tabular}

Trimester specific TSH values were taken into consideration. First trimester 0.05-2.5 $\mu \mathrm{IU}$, second and third trimester $0.18-3 \mu \mathrm{IU}$ were considered normal. TSH values more than $2.5 \mu \mathrm{IU}$ in first trimester and more than $3 \mathrm{mU}$ in second and third trimester with normal free $\mathrm{T}_{3}$ and $\mathrm{T}_{4}$ were diagnosed as subclinical hypothyroidism. TSH more than $4.5 \mu \mathrm{IU}$ with low free T3 and T4 were diagnosed overt hypothyroidism. TSH less than $0.01 \mu \mathrm{IU}$ were diagnosed hyperthyroidism.

The study was approved by ethical committee of RRMCH.

\section{Statistical methods}

Descriptive and inferential statistical analysis was carried out in the present study. Results on continuous measurements were represented on Mean \pm SD (MinMax) and results on categorical measurements were presented in Number (\%). Significance was assessed at 5 $\%$ level of significance. Chi-square/Fisher Exact test were used to find the significance of study parameters on categorical scale between two or more groups.

Statistical software: The statistical software namely SAS 9.2, SPSS 15.0, Stata 10.1, MedCalc 9.0.1, Systat 12.0 and $\mathrm{R}$ environment ver. 2.11.1 were used for the analysis of the data and Microsoft word and Excel have been used to generate graphs, tables etc.

\section{RESULTS}

A total of thousand pregnant women were included in the study. One hundred and twenty six women were detected to have high TSH values. Twenty six women with hypothyroidism were detected anti TPO antibody positive, one woman had hyperthyroidism. Prevalence of hypothyroidism was $7.5 \%$ and autoimmunity was $12.8 \%$ in this study. 
Table 2 shows the demographic details of the mothers with high TSH and thyroid autoimmunity. Mean maternal age was similar in both study groups, around 25-26 years. Most of the women were antenatal booked cases (88\%) in both groups. Most women included in the study had BMI of 24.9 in both groups. Most women in Anti TPO positive group were multigravida $(60 \%)$. Most of them had bad obstetric history.

Table 2: Demographic details and clinical characteristics.

\begin{tabular}{|lll|}
\hline Variables & $\begin{array}{l}\text { Anti TPO } \\
\text { positive (26) }\end{array}$ & $\begin{array}{l}\text { Anti TPO } \\
\text { negative (100) }\end{array}$ \\
\hline Age & 25.4 years & 26 years \\
\hline Booked cases & $88 \%$ & $90 \%$ \\
\hline Parity index & Multi $(60 \%)$ & Primi $(60 \%)$ \\
\hline BMI & $24.9(82 \%)$ & $24(75 \%)$ \\
\hline
\end{tabular}

Table 3 shows association of Thyroid autoimmunity with High TSH. $\mathrm{n}=21$ women $(80.5 \%)$ with anti TPO positive had subclinical hypothyroidism. $n=5(18.5 \%)$ of them had overt hypothyroidism and $n=1(1 \%)$ had hyperthyroidism. 100 women with anti TPO negative had subclinical hypothyroidism.

Table 3: Association of autoimmunity and TSH values.

\begin{tabular}{|lll|}
\hline TSH & $\begin{array}{l}\text { Anti TPO } \\
\text { positive }\end{array}$ & $\begin{array}{l}\text { Anti TPO } \\
\text { negative }\end{array}$ \\
\hline $2.5-5 \mathrm{mU}$ & $21(80.5 \%)$ & $100(100 \%)$ \\
\hline$>10 \mathrm{mU}$ & $5(19.2 \%)$ & - \\
\hline
\end{tabular}

Table 4 shows association of thyroid autoimmunity and adverse maternal outcome. $46.2 \%$ women with anti TPO positive had pre-eclampsia, $\mathrm{p}$ value $<0.001 .7 .7 \%$ women with anti TPO positive had GDM, P value $0.6 .3 .8 \%$ women with anti TPO positive had anaemia, $\mathrm{P}$ value 1.0.

Table 4: Comparison of maternal complications with thyroid autoimmunity.

\begin{tabular}{|llll|}
\hline Outcome & $\begin{array}{l}\text { Anti-TPO } \\
\text { positive }\end{array}$ & $\begin{array}{l}\text { Anti-TPO } \\
\text { negative }\end{array}$ & P value \\
\hline No Complication & $4(15.4 \%)$ & $47(47 \%)$ & \\
\hline PE & $12(46.2 \%)$ & $10(10 \%)$ & $<0.001$ \\
\hline Anaemia & $1(3.8 \%)$ & $7(7 \%)$ & 1.00 \\
\hline GDM & $2(7.7 \%)$ & $4(4 \%)$ & 0.603 \\
\hline
\end{tabular}

Table 5: Comparison of neonatal complications with thyroid autoimmunity.

\begin{tabular}{|lll|l|}
\hline Outcome & $\begin{array}{l}\text { Anti-TPO } \\
\text { positive }\end{array}$ & $\begin{array}{l}\text { Anti-TPO } \\
\text { negative }\end{array}$ & P value \\
\hline IUD & $2(7.7 \%)$ & - & 0.042 \\
\hline IUGR & $4(15.4 \%)$ & $3(3 \%)$ & 0.033 \\
\hline SGA & $3(11.5 \%)$ & $9(9 \%)$ & 0.71 \\
\hline
\end{tabular}

Table 5 shows association of thyroid autoimmunity with adverse fetal outcomes. 7.7\% had IUD; P value 0.042. $15.4 \%$ had IUGR, $\mathrm{P}$ value 0.033 . $\mathrm{n}=3$ had $\mathrm{SGA}, \mathrm{P}$ value 0.71 .

\section{DISCUSSION}

In this study prevalence of hypothyroidism and thyroid autoimmunity were obtained and its relation to adverse outcomes such as PE, GDM, IUGR, SGA were studied.

Prevalence of hypothyroidism was $7.5 \%$ in this study. Studies of Dinesh Dhanwal et al., Sahu et al. and Nambiar et al. showed prevalence of $6.5 \%, 6.4 \%$ and $4.8 \%$ respectively. ${ }^{3,4}$ Prevalence of thyroid autoimmunity was $12.8 \%$ in our study. Similar results were obtained in studies of Nambiar et al. Studies of Lavanya et al. showed a prevalence of $51 \% .{ }^{18}$ Prevalence of subclinical hypothyroidism in women with thyroid autoimmunity was $12.6 \%$ in our study. Prevalence of thyroid autoimmunity and subclinical hypothyroidism was $18.5 \%$ in studies of Dhanwal et al. ${ }^{3}$

We found increased risk of PE in women with hypothyroidism and thyroid autoimmunity. $46.2 \%$ of women with anti TPO antibodies positive had PE in comparison to $10 \%$ with anti TPO Negative P value $<0.001$. Studies of Mecacci et al. and Karkosta et al. showed $33.3 \%$ and $4.7 \%$ of women with thyroid autoimmunity had PE respectively. Indian studies showed similar results. ${ }^{8,13,14}$ Studies of Alwin Azi showed no significance of thyroid autoimmunity and hypothyroidism in prevalence of PE. ${ }^{10,11}$

In our study $7 \%$ of women with anti TPO antibody negative had preterm delivery. Studies of Wang et al. and Alex Stangaro Green showed similar results. ${ }^{9}$ There are many studies showing relation between autoimmunity and preterm labor. Pregnancy represents an inflammatory process with a shift in the regulation of cytokine networks within the local placental-decidual environment, a deregulation of the local inflammatory processes can be associated with miscarriage and premature delivery. ${ }^{7,8}$

In our study $7.7 \%$ of women with thyroid autoimmunity had GDM in comparison to $4 \%$ without autoimmunity, $\mathrm{p}$ value of 0.603 in this study. Studies of Oliveria et al., Agarwal et al., Karkosta et al., showed 16\% and 20.2\%, $8.8 \%$ of women with autoimmunity developed GDM. ${ }^{11,12,8}$ Studies of Maratou and colleagues has shown decreased rate of insulin stimulated glucose transport inside cells of hypothyroid patient. ${ }^{15}$

Present study showed increased prevalence IUGR and SGA babies $9.24 \%$ and $6.9 \%$ respectively in women with hypothyroidism and autoimmunity. Studies of Karkosta et al. showed prevalence of $5.4 \%$ and $5.1 \%$ respectively. ${ }^{8,16}$ Thyroid hormone is essential for growth of all vital organs, deficiency of thyroid hormone can cause negative effect on pituitary thyroid axis of new- 
born and interferes with the normal vascular responsiveness and cardiovascular homeostasis of the fetus. $^{16}$

\section{CONCLUSION}

High prevalence of hypothyroidism and Thyroid autoimmunity during pregnancy makes it an important health problem. Most of the thyroid dysfunctions manifest during pregnancy and they go undiagnosed as most symptoms may mimic symptoms related to pregnancy. Early screening of thyroid function and timely initiation of treatment can prevent maternal and fetal complication and improve outcomes.

Funding: No funding sources

Conflict of interest: None declared

Ethical approval: The study was approved by the ethical committee of RRMCH

\section{REFERENCES}

1. Van den Boogaard E, Vissenberg $\mathrm{R}$ et al. Significance of (sub) clinical thyroid dysfunction and thyroid autoimmunity before conception and in early pregnancy: a systematic review. Human Reproduc Update. 2011;17(5):605-19.

2. Unnikrishnan AG, Kalra $S$ et al. Prevalence of hypothyroidism in adults: an epidemiological study in eight cities of India: Indian J Endocrinol Metabol. 2013;32(192):397-403.

3. Dhanwal DK, Prasad S, Agarwal AK, Dixit V, Banerjee AK. High prevalence of subclinical hypothyroidism during first trimester of pregnancy in North India: Indian J Endocrinol Metabol. 2013 Mar;17(2):281-4.

4. Sahu MT, Das V, Mittal S, Agarwal A, Sahu M. Overt and subclinical thyroid dysfunction among Indian pregnant women and its effect on maternal and fetal outcome. Arch Gynaecol Obstet. 2010 Feb;281(2):215-20.

5. Khalid A El Baba, Sami T Azar. Thyroid dysfunction in pregnancy. Int J Intern Med. 2012;5:227-30.

6. Pietro cignini, Ester Valentina Cafa et al. Thyroid physiology and common diseases in pregnancy: review literature: J Prenat Med. 2012;6(4):64-71.

7. Donny L. Chang, Elizabeth N. Pearce. Screening for maternal Thyroid dysfunction in pregnancy: a review of the clinical evidence and current guidelines. J Thyroid Res. 2013;2013:851326.

8. Karakosta P, Alegakis D, Georgiou V, Roumeliotaki T, Fthenou E, Vassilaki M, Boumpas D, Castanas E, Kogevinas M, Chatzi L. Thyroid dysfunction and autoantibodies in early pregnancy are associated with increased risk of gestational diabetes and adverse birth outcomes: J Clin Endocrinol Metabol. 2012 Dec;97(12):4464-72.

9. He X, Wang P, Wang Z, He X, Xu D, Wang B. Thyroid antibodies and risk of preterm delivery: a meta-analysis of prospective cohort studies. Euro J Endocrinol. 2012 Oct;167(4):455-64.

10. Alavi A, Adabi K, Nekuie S, Jahromi EK, Solati M, Sobhani A, Karmostaji H, Jahanlou AS. Thyroid dysfunction and autoantibodies association with hypertensive disorders during pregnancy. J Pregnancy. 2012;2012:742695.

11. Agarwal MM, Dhatt GS, Punnose J, Bishawi B, Zayed R. Thyroid function abnormalities and antithyroid antibody prevalence in pregnant women at high risk for gestational diabetes mellitus. Gynecol Endocrinol. 2006 May;22(5):261-6.

12. Olivieri A, Valensise H, Magnani F, Medda E, De Angelis S, D'Archivio M, Sorcini M, Carta S, Baccarini S, Romanini C. High frequency of antithyroid autoantibodies in pregnant women at increased risk of gestational diabetes mellitus. Euro J Endocrinol. 2000 Dec;143(6):741-7.

13. Mecacci F, Parretti E, Cioni R, Lucchetti R, Magrini A, La Torre P, Mignosa M, Acanfora L, Mello G. Thyroid autoimmunity and its association with nonorgan-specific antibodies and subclinical alterations of thyroid function in women with a history of pregnancy loss or preeclampsia. $\mathrm{J}$ Reproduc Immunol. 2000 Feb;46(1):39-50.

14. Muthukrishnan Jayaraman, Abhyuday Verma, K. V. S. Harikumar, Meena Ugale, Kirtikumar Modi. Pregnancy outcomes with thyroxin replacement for subclinical hypothyroidism: role of thyroid autoimmunity: Indian J Endocrinol Metabol. 2013 Mar-Apr;17(2):294-297.

15. Lambadiari V, Mitrou P, Maratou E, Raptis AE, Tountas N, Raptis SA, Dimitriadis G. Thyroid hormones are positively associated with insulin resistance early in the development of type 2 diabetes. Endocrine. 2011;39:28-32.

16. Blazer S, Moreh-Waterman Y, Miller-Lotan R, Tamir A, Hochberg Z. Maternal hypothyroidism may affect fetal growth and neonatal thyroid function. Obstet Gynaecol. 2003 Aug;102(2):232-41.

17. Gayathri R, Lavanya S, Raghavan K. Subclinical hypothyroidism and autoimmune thyroiditis in pregnancy: a study in south Indian subjects. J Assoc Physicians India. 2009 Oct;57:691-3.

DOI: 10.5455/2320-1770.ijrcog20140606

Cite this article as: Sailakshmi MPA, Pavana

Ganga A, Rekha BR, Akash SS. Autoimmune thyroid disease in pregnancy. Int J Reprod Contracept Obstet Gynecol 2014;3:321-4. 